\title{
Design for Creating, Uploading and Sharing User Generated Content
}

\author{
Marianna Obrist \\ ICT\&S Center, Univ. Salzburg \\ Sigmund-Haffner-Gasse 18 \\ 5020 Salzburg, Austria \\ marianna.obrist@sbg.ac.at

\section{David Geerts} \\ Centre for Usability Research \\ Parkstraat 45 Bus 3605 \\ 3000 Leuven, Belgium \\ david.geerts@soc.kuleuven.be \\ Petter Bae Brandtzæg \\ SINTEF ICT \\ Forskningsvn 1b \\ 0134 Oslo, Norway \\ pbb@sintef.no

\section{Manfred Tscheligi} \\ ICT\&S Center, Univ. Salzburg \\ Sigmund-Haffner-Gasse 18 \\ 5020 Salzburg, Austria \\ manfred.tscheligi@sbg.ac.at
}

Copyright is held by the author/owner(s).

CHI 2008, April 5 - April 10, 2008, Florence, Italy

ACM 978-1-60558-012-8/08/04.

\begin{abstract}
The power of users playing the roles of authors and editors is undeniable these days [1]. New media, not only the Internet, are enabling people to become active users related to content production and sharing, and in co-creation of User Generated Content (UGC). In particular younger users and heavy users of Internet use networked applications to create and share content [1]. There is a need for UGC applications targeting a broader market, including older users and average Internet users. Today, the knowledge in designing and building for co-creation in networked media is still rather weak. The lack of information about UGC characteristics makes it difficult to expect what kind and amount of content will be produced, and to understand and interpret the reasons why users and user communities arise or fail. A significant effort is currently made by the HCI community in order to support active user involvement into the design and evaluation of networked applications [6]. Nonprofessional users are encouraged to become active producers and designers themselves [1]. However, there is still the need to explore how to apply and further extend these approaches and methods to better understand, design for and evaluate UGC applications. This SIG will contribute to this discussion by actively involving the audience in UGC creation.
\end{abstract}




\section{Keywords}

Co-Creation, User Generated Content, Media, NonProfessional Users, End User Involvement, Design and Evaluation Methods

\section{ACM Classification Keywords}

H5.2 User interfaces: Theory and methods, H.5.3 Group and Organization Interfaces: Collaborative computing

\section{Introduction}

In particular social networking and community websites have changed the way people use new media, in creating personal profiles, sharing photos, videos, blogs and user generated content (UGC) in general. The most visited UGC sites in 2007 (according to Alexa Internet, December 2007) are MySpace, Facebook and YouTube. Facebook is a social networking site attracting more than 60 million members, while MySpace, with a music profile targeting has more than 300 million members world wide. YouTube, with opportunities for uploading and video sharing, has also been increasingly popular during 2006 and 2007.

The new content creators are non-professional users, who create and share UGC in small communities for a limited audience. The non-professional users [5] (as opposite to the professional media-producer) evolve from being passive consumers of mainstream media content to taking an active role in the new media chain. Triggered by the widespread availability of digital recording devices, end-users will be both the largest content producers and consumers of the future. A big challenge for the CHI-community approaching "The Long Tail" model is how these non-professional users, including not only young and heavy Internet users but also older and average Internet users, can be supported in co-creating and sharing media content [1]. Supporting non-professional users in becoming active producers and co-creators is also discussed within the HCI community, especially in the End-UserDevelopment (EUD) field, as an important topic for future user involvement [3].

UGC moves design toward a more user-centric approach. There is still a need to investigate this approach to better understand, design for and evaluate UGC applications. Several research topics are of relevance regarding UGC by non-professional users. Thousands of personal blogs, vlogs or accounts on sharing sites are created every day, but a lot of them have a very short time-span. This raises the question how user motivation and participation can be inspired for continued use. Recent academic work exploring participation, motivations for usage and production of UGC, or even who these users are, is scarce [3]. A newly published study by Oded Nov [5] entitled "What Motivates Wikipedians?" suggested fun as an important aspect in explaining why people contribute UGC. However, a limitation of this study is that it only focuses on users of Wikipedia, a quite specialized community including mainly highly educated users. The Wikipedia study therefore does not cover or explain active creation among ordinary users attending in UGC sites. Another study of more mainstream users of UGC found three main barriers to user participation: 1) Lack of interesting people/friends attending, 2) Low quality content, and 3) Low usability [3]. An important usercentred challenge is therefore the transition between passive consumption and active participation in terms of not only usability issues, but also how different kinds of websites and even media channels may influence the user contributions of different types of UGC and 
motivations to participate with UGC [3]. Another crucial aspect is the social interaction that plays an important role in sustaining these small communities, and how social interaction can be supported [3], through the interface by enhancing the sociability and coexperience. This also requires a better understanding of the nature of what UGC in terms of co-creation actually is and how it can be characterized.

We believe that UGC can provide users with a new user experience by challenging $\mathrm{HCI}$ designers to develop new techniques and methods to approach UGC by for instance:

1) Exploring new methods, tools and techniques for capturing user and context requirements for UGCapplications.

2) Developing a framework for the design of user interfaces on different platforms and devices for demonstrating the concept of the UGC experience.

3) Involving users and communities into the design process of UGC applications by following a more individual-centered approach.

4) Producing evaluation results on UGC by advanced evaluation methods, and by engaging users as evaluators.

From our own current research in the EU IST CITIZEN MEDIA project, as well as from former research, we know that a lot of users are not satisfied with simply being passive consumers, but rather want to be active producers [7]. We will therefore need a new approach and methods to be able to evaluate this user trend; we need to move from easy-to-use to easy to participate/produce/co-create.

\section{Related Events}

At CHI 2007, we have organized a workshop on a similar topic: "Supporting non-professional users in the new media landscape". The workshop was related to the CHI 2006 workshop on end-user development, but the focus of the CHI 2007 workshop was on media applications. The workshop "Shared Encounters" at CHI 2007 also relates to this SIG. This workshop dealt with social networks and sharing of experiences. We have significant experience in this co-creation domain, and will discuss similarities and differences to foster participation from the audience.

\section{SIG Audience}

One of the goals of this SIG is to identify and gather people interested in the field of $\mathrm{HCI}$ for designing cocreation of UGC, as well as researchers interested in the maturation of the $\mathrm{HCI}$ perspective on emerging networked media technologies. We foresee the following types of participants:

- Practitioners working in the design, development and evaluation of UGC media or interactive systems. We welcome both practitioners coming from the "engineering side" of emerging systems as well as practitioners with a background in "user interface design and evaluation".

- Academics working or interested in state of the art and research activities in the field of UGC and cocreation of shared media, UGC networks and evaluation of a new evolving user experience.

The audience would be approximately 50-150 professionals and academics interested in how to design for creating, uploading and sharing UGC in order 
to improve user involvement, usability and user experience of emerging networked systems.

\section{SIG Organization}

The activity plan for the SIG is as follows:

- Introduction of the panel and goals of the SIG (10 minutes).

- Lively presentation by the organizers of issues in the various fields related to the topic of the SIG, like co-creation of user generated media content with practical case examples, HCI approaches, design and evaluation techniques as well as examples of co-creating media (20 minutes)

- The organizers will create media content before the SIG (e.g. at several CHI 2008 sessions) as well as during the SIG, especially pictures and video, by using their own camera-phones, photo cameras and video cameras. These media will be combined, uploaded and shared on popular UGC websites on the spot, to identify the user experience issues that need attention of the HCI community. This will provide an excellent context for discussing specific user interface issues when creating, editing, uploading and sharing UGC.

- Simultaneously with the activity on UGC sites, a structured interactive discussion will be held with the participants to list the issues related with cocreation of user generated media content in order to inform the design and evaluation of UGC applications. The relevant usability and user experience issues will be discussed, those that seem more important will be selected, and comments on the solutions will be stored (50 minutes).
- Wrap up of the discussion and creation of future plans, in particular on joint actions on this topic among those who are interested (10 minutes).

The organizers have extensive experience in organizing interactive workshops and discussions, such as workshops and SIGs at CHI 2006, Ubicomp 2006, CHI 2007, EuroITV 2007.

\section{Acknowledgements}

We would like to thank all partners in the CITIZEN MEDIA project (funded by FP6-2005-IST-41).

\section{References}

[1] Anderson, C. The Long Tail. How Endless Choice is Creating Unlimited Demand. Random House Business Books, 2006.

[2] Brandtzæg, P.B., and Heim, J. User Loyalty and Online Communities: Why Members of Online Communities are not faithful. INTETAIN. Proceedings of the 2008 ICST Second International Conference on Intelligent Technologies for Interactive Entertainment, ACM press, 2008.

[3] Heim, J., and Brandtzæg, P. B. Patterns of Media Use and the Non-professional Users. Paper presented at Supporting non-professional users in the new media landscape. Workshop at CHI '07, 2007.

[4] Lieberman, H., Paternó, F., and Wulf, V. (Eds.). End User Development. Springer/Kluwer Academic Publishers, 2006.

[5] Nov, O. What motivates Wikipedians? Communications of the ACM. 50, 11 (2007), 60-64.

[6] Visser, F. S., and Visser, V. Re-using users: cocreate and co-evaluate. Personal and Ubiquitous Computing. Vol. 10 (2006), 148-152.

[7] Von Hippel, E. Democratizing Innovation. Cambridge/London: MIT Press, 2005. 